\title{
Avaliando ações de segurança viária através de indicadores
}

\author{
M. C. Diógenes ${ }^{1}$ e L. A. Lindau ${ }^{2}$ \\ Universidade Federal do Rio Grande do Sul, Laboratório de Sistemas de Transportes, Porto Alegre, Rio Grande \\ do Sul, Brasil
}

Artigo Recebido: 10/09/2004 - Aprovado: 15/04/2005

RESUMO: O problema da insegurança viária é uma preocupação constante de vários setores da sociedade. Organizações do setor público, privado e Terceiro setor realizam ações de prevenção dos acidentes viários ou de redução de seus impactos negativos. Porém, ainda não se sabe definir com precisão a contribuição destas ações para a melhoria da segurança viária. A literatura recomenda o uso de indicadores de desempenho para monitorar os resultados destas ações, e assim, auxiliar os processos de tomada de decisão. Este trabalho tem como objetivo apresentar como os indicadores de desempenho se inserem no contexto da segurança viária, através da proposição de indicadores de segurança viária para uma organização não governamental, a Fundação Thiago de Moraes Gonzaga. Esta fundação atua principalmente na educação para o trânsito e conscientização de jovens. A metodologia, aqui desenvolvida, pode servir de modelo para criação de sistemas similares de indicadores em outras organizações de segurança viária.

ABSTRACT: Road safety is an aspect that concerns several sectors of the society. Public and private organizations, as well as third sector agencies, are in charge of implementing actions to prevent the occurrence and severity of road accidents. However, still very little is known regarding the contribution of these actions to the improvement of road safety. The literature suggests the use of performance indicators to monitor the results of these actions and help the decision making process. The objective of this paper is to show the way performance indicators can be inserted into the context of road safety. This is achieved through the proposition of road safety indicators to a non-governmental organization, i.e. Fundação Thiago de Moraes Gonzaga. This foundation deals with activities related to traffic education, particularly those aimed at young people. The proposed methodology can be used to help the development of similar systems in other organizations that deal with road safety.

\section{INTRODUÇÃO}

Os acidentes decorrentes do trânsito viário são um dos fatores de risco da vida e saúde humana e são considerados como a principal causa de morte entre os jovens (Peden et al., 2004). Visando atenuar o risco de ocorrência de acidentes, medidas mitigadoras são propostas e implementadas. Estas medidas fazem parte do gerenciamento da segurança viária, cujo estilo pode ser pragmático, processo da tomada de decisões baseado na intuição ou na experiência dos técnicos, ou racional, onde as decisões são fundamentadas em estudos e pesquisas que quantificam e qualificam as consequiências das ações.

Critica-se a prevenção de acidentes baseada no modelo pragmático. A crítica reside no fato de ela poder se caracterizar como perda de tempo ou mesmo ocasionar efeitos negativos, que podem resultar piores do que a opção "não fazer nada". Um dos argumentos para a não utilização da intuição prende-se na dimensão do problema acidente viário, que é bastante complexo para ser tratado pelo método da tentativa e erro (JAT, 2000). Campos (1992) reforça esta idéia afirmando que os processos decisórios de qualquer organização devem se fundamentar em dados e fatos concretos e não em experiências, bom senso, intuição ou coragem. Isto justifica a necessidade do desenvolvimento de pesquisas que visem avaliar a eficiência e eficácia das ações voltadas à melhória da segurança viária.

Os sistemas de avaliação de desempenho permitem mensurar a eficiência e eficácia das ações de qualquer organização. Estes sistemas foram inicialmente 
utilizados pelo setor privado, porém atualmente são usados também no setor público e Terceiro setor. Em países em desenvolvimento, tais como o Brasil, ainda são observadas dificuldades e resistências, especialmente no setor público, à implantação de indicadores, principalmente nas áreas de saúde, educação, segurança pública e transportes (Amouzou e Pérez, 1999).

No que se refere às organizações atuantes no campo da segurança viária, é mais comum avaliar o sistema de transportes como um todo, através de estatísticas relacionadas à ocorrência de acidentes, como, por exemplo, número de colisões e de acidentes envolvendo lesões e fatalidades. Embora estas medidas sejam necessárias, elas são insuficientes para ponderar se as ações tomadas estão atingindo o objetivo de mitigar os acidentes (Rumar, 1999; ETSC, 2001b; OECD, 2002; Aeron-Thomas, 2003). Além disso, essas estatísticas freqüentemente estão baseadas em banco de dados incompletos, como é o caso do Brasil, onde há descontinuidade nos registros de acidentes, duplicidade e armazenamento não digital dos dados.

Surge, então, a necessidade de criar sistemas de indicadores capazes de mensurar o alcance dos objetivos para o qual uma medida foi tomada. Por exemplo, se for iniciada uma campanha que objetive induzir o uso do cinto de segurança, deve-se mensurar a modificação da taxa de utilização deste equipamento. Dentro desta perspectiva, buscou-se elaborar uma proposta de indicadores de segurança viária para avaliar as ações realizadas pela Fundação Thiago de Moraes Gonzaga (FTMG). A metodologia utilizada baseou-se na estruturação lógica de montagem de indicadores de segurança viária proposta por Diógenes e Lindau (2003).

O trabalho inicia com um breve histórico da FTMG, situando-a no contexto das ONGs de segurança viária. Depois, apresenta-se a metodologia adotada para a proposição de indicadores.

\section{FUNDAÇÃO THIAGO DE MORAES GONZAGA}

As organizações não governamentais (ONGs) surgem para suprir as ineficiências do poder público ou para expor razões ideológicas (Carvalho, 1999). Na área da segurança viária, experiências mostraram que as ONGs tendem a atuar em áreas onde as autoridades públicas apresentam dificuldades, seja por falta de recursos ou por descrédito da população nos políticos (Ellevset, 1997). Geralmente, as ONGs de segurança viária concentram suas atividades em quatro áreas: (i) educação e conscientização pública; (ii) reivindicações por melhores condições de segurança viária; (iii) policiamento (através de denúncias); e (iv) desenvolvimento de pesquisas e propostas de alternativas para o tratamento da segurança viária.

A Organização Mundial de Saúde (OMS, 2002) propôs que as ONGs devam atuar tanto na prevenção de acidentes quanto na defesa de vítimas. Por exemplo, The Globe (2003) afirma que "as ONGs de segurança viária são capazes de estruturar grupos de advocacia para auxiliar as vítimas do trânsito de forma mais eficiente do que o Estado". Algumas ONGs ainda atuam em outras áreas, tais como: (i) modificação das leis do trânsito de um país; (ii) promoção de pesquisas em segurança viária; e (iii) tratamento e reabilitação de vítimas e familiares (Aeron-Thomas, 2003).

Foi dentro deste contexto, que no início da década de 80, as ONGs e grupos de pesquisadores começaram a exercer um importante papel no campo da segurança viária, resultando em inúmeras experiências bem sucedidas (ETSC, 2001a). Muitas destas entidades atuam junto aos jovens, pois se acredita que ações de conscientização voltadas para este público alvo sejam a solução chave para diminuir a incidência e severidade dos acidentes (Kroj, 2000). É justamente neste campo que atua a organização americana Mothers Against Drunk Driving (MADD) e a Fundação Thiago de Moraes Gonzaga (FTMG), objeto de estudo deste trabalho.

A MADD foi criada em 1980 nos Estados Unidos. Ela foi idealizada para atuar contra os crimes do trânsito envolvendo o problema álcool-direção, através da mobilização de vítimas e familiares de vítimas de acidentes viários. Em 1999 a missão da MADD foi modificada para: "fazer com que as pessoas parem de dirigir sob o efeito do álcool, apoiar vítimas deste crime violento, e prevenir o consumo de álcool por menores de idade" (Lord, 2000; MADD, 2003).

A FTMG foi criada em 1996 em Porto Alegre, e desde então, recebe prêmios como forma de reconhecimento de sua importância para a sociedade, tais como o XI Prêmio Volvo de Segurança no Trânsito, na Categoria Geral no ano de 2000 (Volvo, 2004). A fundação atualmente realiza ações em mais de 156 municípios gaúchos e contém vários núcleos espalhados pelo estado do Rio Grande do Sul. Além disso, foram estabelecidas parcerias em São Paulo e em Brasília, e criados núcleos nestas cidades.

A história da FTMG remonta a um acidente viário ocorrido na madrugada do dia 20 de maio de 1995 , em Porto Alegre. $O$ incidente foi conseqüência da colisão de um automóvel, com velocidade superior a $100 \mathrm{~km} /$ h, e um contêiner de entulho irregularmente localizado em uma interseção da capital gaúcha. Este resultou na morte de dois jovens: Thiago de Moraes Gonzaga e Rodrigo Malinski. Segundo Ferlauto (1996), o motorista, não lesionado, era um jovem sob efeito do álcool e não habilitado a dirigir; ainda, as vítimas eram passageiros do veículo e não utilizavam cinto de segurança.

Após a morte de Thiago, seus pais, Régis e Diza Gonzaga tiveram a iniciativa de criar a FTMG, cujo principal objetivo era o de desenvolver ações de conscientização pública visando a redução da incidência dos acidentes com lesões ou fatalidades, envolvendo jovens entre 15 e 25 anos. Para atender os 
objetivos idealizados na concepção da fundação foi lançado o livro que conta a história de Thiago (Ferlauto, 1996), e criada a campanha "Vida Urgente".

A campanha "Vida Urgente" esteve focada inicialmente na questão do problema álcool-direção entre os jovens e baseou-se em frases que poderiam ser facilmente assimiladas por este grupo alvo: "A timidez não é a única coisa que você perde quando bebe. Logo depois, perde os reflexos e a percepção da distância. Por isso, se beber, não dirija" (Gonzaga, 2003). Depois, foi ampliada para abranger a questão de alta velocidade e uso do cinto de segurança. A crescente procura de pais, cujos filhos morreram em acidentes, por apoio na FTMG incentivou a criação de uma atividade de apoio psicológico e, nesse momento, almeja-se criar atividades de apoio jurídico às famílias das vítimas. Atualmente, a campanha "Vida Urgente" é composta por 14 atividades, que podem ser agrupadas em (Diógenes, 2004):

Atividades de conscientização dos jovens: todas as ações cujo objetivo principal seja inibir ou mesmo impedir que os jovens peguem carona com alguém que esteja alcoolizado ou dirijam sob o efeito do álcool. Neste grupo estão: Madrugada Viva, Bloco de Carnaval e Buzoom.

- Atividades de educação para o trânsito: todas as ações cujo foco é a educação das crianças: Projeto "Contadores de Histórias" e "Seminário Adolescência em Debate".

- Atividades de apoio psicológico: ações destinadas a prover conforto aos familiares de vítimas do trânsito: Grupo de Apoio Voluntário e de Reflexão.

- Atividades de integração dos voluntários: atividades que visam o engajamento de voluntários à missão organizacional: Encontro dos Voluntários e Vida Urgente Acústico.

- Atividades de conscientização dos motociclistas: ações destinadas a alertar motoristas e empregadores dos perigos do trânsito: Moto Vida.

- Atividades de conscientização pública: ações cuja finalidade é conscientizar a sociedade do dever da responsabilidade no trânsito, embora muitas vezes o jovem seja o mais focado. São elas: Espetáculo Teatral "Exército de Sonhos", Expo Vida Urgente, Escola Urgente, Vida Urgente In Concert e Palestras.

A atividade Madrugada Viva é uma das mais conhecidas da campanha. Esta atividade ocorre nas madrugadas de sexta-feira, e caracteriza-se pela ida de grupos de 50 a 60 jovens voluntários, sob a coordenação de funcionário da fundação, aos locais freqüentados por pessoas da faixa etária de 15 a 25 anos, para passar a mensagem da FTMG. Os voluntários abordam os freqüentadores e falam sobre segurança no trânsito, enfatizando o perigo do uso do álcool ao volante, a necessidade do uso do cinto e de respeito dos limites de velocidade. Após a conversa, os abordados recebem folhetos informativos e são convidados a fazer o teste do bafômetro. Aqueles que passam no teste ganham um adesivo verde escrito "Carona segura, estou de cara limpa", e os que não passam ganham um adesivo vermelho escrito "Tomei todas, quero carona". Os voluntários que participam desta atividade têm entre 15 e 25 anos. E importante ressaltar que, por questões orçamentárias, esta atividade ocorre apenas ao longo de algumas semanas do ano.

Informações sobre as outras atividades podem ser encontradas na homepage da FTMG (http:// www.vidaurgente.com.br) ou em Diógenes (2004).

\section{METODOLOGIA PARA INDICADORES DA FTMG}

O desenvolvimento e a utilização de indicadores de desempenho contempla três etapas essenciais: (i) a seleção de indicadores; (ii) o desenvolvimento de um sistema confiável de coleta e armazenamento de dados; e (iii) a inserção dos indicadores nos processos de tomada de decisão. Estas etapas envolvem conhecimentos técnicos e a modificação da cultura organizacional no que se refere à coleta de dados, resultando, portanto, em um processo contínuo e demorado.

Diógenes e Lindau (2003), através de revisão bibliográfica, estabeleceram as principais etapas que devem ser realizadas no processo de desenvolvimento de segurança viária: (i) identificação da área problema; (ii) estabelecimento dos objetivos; (iii) desenvolvimento de programas e ações de segurança viária; (iv) seleção e aplicação dos indicadores; (v) estabelecimento de medidas-alvo; e (vi) atualização do sistema de indicadores. Neste processo, é importante que os indicadores selecionados estejam correlacionados aos objetivos.

A FTMG, em sua concepção, já havia identificado a área problema e desenvolvido seus programas e ações de segurança viária. Assim as etapas anteriormente descritas foram adaptadas para a realidade da organização. De uma forma geral, a metodologia utilizada para o estabelecimento dos indicadores da fundação encontra-se ilustrada na Figura 1.

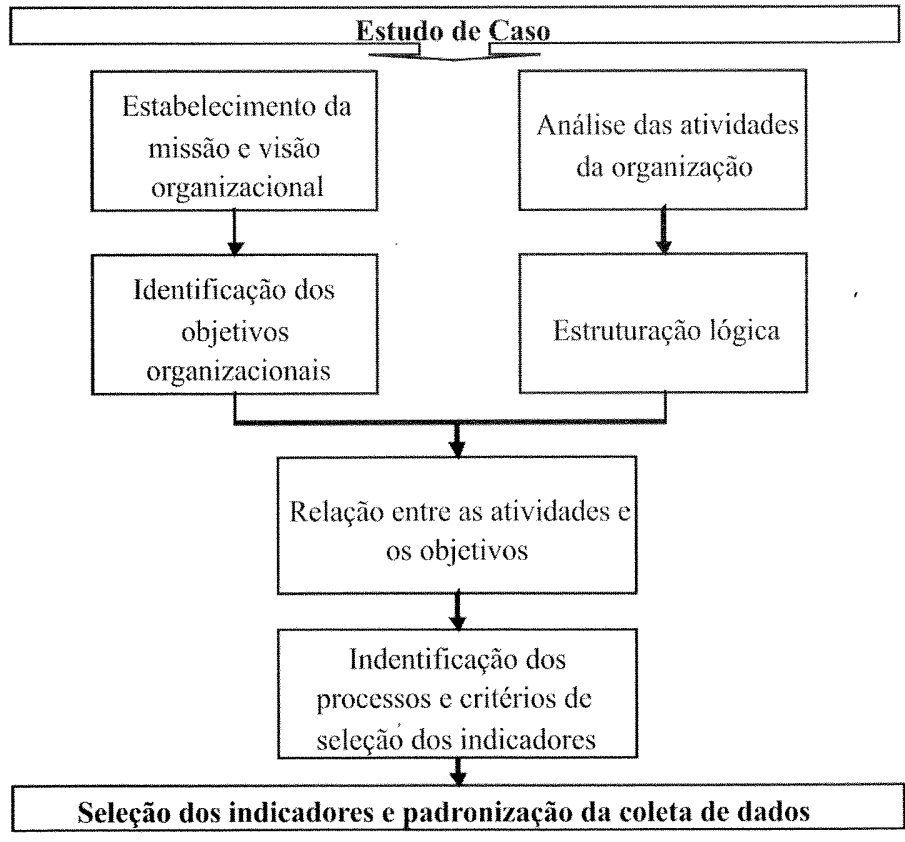

Figura 1. Metodologia de seleção dos indicadores. 
A análise das atividades visou identificar os objetivos das ações desenvolvidas através de uma estruturação lógica, e, assim estabelecer sua relação com os objetivos organizacionais. Esta estruturação lógica foi proposta pelo World Bank (1996) e estabelece uma ligação entre as entradas, saídas, resultados e impactos das atividades.

Para fins de simplificação, neste trabalho apresenta-se apenas a análise da estrutura lógica da atividade Madrugada Viva, conforme a Figura 2. Já em Diógenes (2004) encontram-se estruturadas as demais atividades da Fundação. No decorrer desta análise, as seguintes premissas foram consideradas:

$\rightarrow$ as entradas das atividades se dividem em outros recursos e voluntários classificados em: (i) psicólogos voluntários; (ii) palestrantes voluntários; (iii) jovens voluntários (entre 15 e 25 anos); (iv) escolas voluntárias; e (v) voluntários (não restrito a idade). Os "outros recursos" compreendem todos os recursos humanos (conselho consultivo, atores contratados e funcionários) e financeiros (patrocínios, contratos, parcerias, espaço físico, transporte);

- os voluntários são atraídos para a FTMG pelas atividades da campanha Vida Urgente;

o engajamento dos jovens à fundação os torna conscientes da necessidade de respeitarem as leis do trânsito. Assim, as atividades que visam integrar os voluntários, além de contribuir para a realização das atividades, geram jovens mais responsáveis com o trânsito;

- a maior conscientização das pessoas faz com que estas não sejam imprudentes no trânsito, tornando o componente humano mais seguro. Isto gera, então, o impacto, que é a redução do risco de acidentes cuja causa é atribuída a falhas humanas.

A etapa de estabelecimento da missão organizacional teve como objetivo explicitar a relação das atividades com os objetivos organizacionais, visto que estas não se encontravam estruturadas dentro de um planejamento estratégico. Analisando os princípios que geraram a criação da fundação, e as mudanças de foco ao longo do tempo, e através de reuniões com os membros da fundação, propôs-se uma redação para a missão organizacional da FTMG (Diógenes, 2004): "agir de forma a diminuir a incidência e/ou severidade de acidentes decorrentes de falhas no fator humano e fornecer apoio às famílias que tiveram suas vidas modificadas pelos acidentes decorrentes do tráfego".

A realização da missão da organização depende de uma série de fatores: (i) recursos financeiros; (ii) voluntários; (iii) atividades de conscientização pública e (iv) apoio psicológico. Vale ressaltar que o corpo de voluntários, além de comprometido com a missão da organização, deve conter jovens entre 15 e 25 anos. Esta premissa fundamentou o estabelecimento das metas e objetivos organizacionais, apresentados na Figura 3, onde se observam as relações entre os objetivos e as atividades da FTMG.

Uma vez expressa a missão, identificados os objetivos e suas relações com as atividades da FTMG, foram determinados os processos e critérios de seleção dos indicadores.

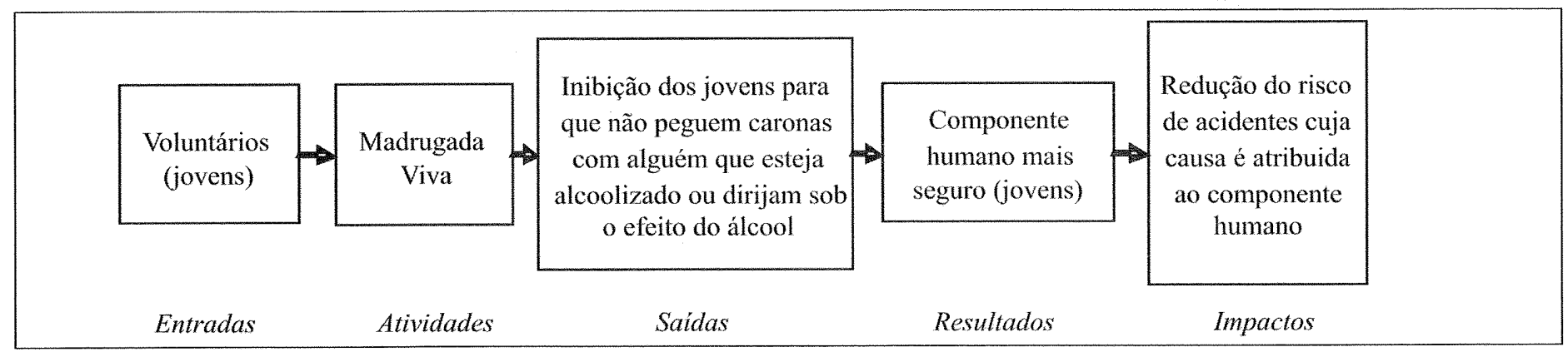

Figura 2. Estrutura lógica da atividade Madrugada Viva.

\section{SELEÇÃO DOS INDICADORES}

Alguns questionamentos são inerentes ao processo de seleção de indicadores. A primeira pergunta a ser respondida, quando da realização desta tarefa é: qual a finalidade do indicador? As respostas clássicas a esta pergunta são: (i) determinar o risco de ocorrência e/ou de severidade de acidentes; (ii) verificar se os veículos atendem aos padrões de segurança; (iii) quantificar o nível de segurança de uma via; (iv) monitorar a modificação de comportamento da sociedade. É natural que outras respostas surjam, tais como, determinar quantas pessoas estão sendo contempladas com programas de educação para o trânsito.

Os indicadores utilizados para avaliar a segurança viária podem ser classificados em indicadores primários e secundários. Os indicadores primários de segurança viária (IPSVs), também denominados indicadores dos impactos ou indicadores estatísticos, podem ser definidos como medidas que estão diretamente relacionadas aos problemas da "insegurança, sendo representados por contagens de acidentes com variáveis de exposição (Lötter, 2000). Já os indicadores secundários de segurança viária (ISSV) mensuram fatores correlacionados com os acidentes, tais como, comportamento do usuário, aspectos legais e tecnologia veicular (Lötter, 2000; ETSC, 2001b). A principal aplicação dos ISSVs é fornecer indícios dos mecanismos que caracterizam a ocorrência dos acidentes, visando fundamentar os processos de tomada de decisão (Stenborg, 1999).

Tanto os indicadores primários quanto os 
secundários são fundamentais para a identificação das causas dos acidentes e para a formulação de estratégias voltadas à proposição de medidas preventivas e mitigadoras. Por exemplo, quando um indicador secundário de comportamento revelar um maior percentual de motoristas dirigindo sob o efeito de bebidas alcoólicas e o primário indicar um acréscimo de acidentes relacionados a este problema, significa que as ações que estão sendo realizadas para erradicar o consumo de álcool por motoristas não estão sendo eficazes, devendo-se modificar a forma como está sendo tratado o problema.

É importante ressaltar que os indicadores de segurança viária destinados a mensurar os resultados e impactos não permitem avaliar com precisão a eficiência e eficácia de uma única ação de forma isolada; outras ações, desenvolvidas antes ou mesmo depois, podem ter efeito sobre o indicador (LTSA, 1998; Aeron-Thomas et al., 2002; ETSC, 2001b,
Norwood e Casey, 2002).

Para a proposição dos indicadores da FTMG, optouse por estabelecer prioritariamente indicadores secundários que estivessem relacionados às saídas das atividades. A mensuração direta dos resultados e impactos seria pouco recomendável, visto que outras organizações também realizam ações voltadas para os mesmos objetivos da FTMG.

Outras perguntas que devem ser respondidas referem-se à possibilidade de coleta de dados e à significância do indicador para mensurar o alcance dos objetivos organizacionais. Isto se deve a três fatores (Diógenes, 2004): (i) os dados para alimentar os indicadores devem ser confiáveis, visto que fundamentar processos decisórios em indicativos mal postados pode ocasionar efeitos indesejáveis à segurança viária; (ii) o sistema de coleta é intrinsecamente oneroso, e, portanto, dados desnecessários representariam desperdícios de

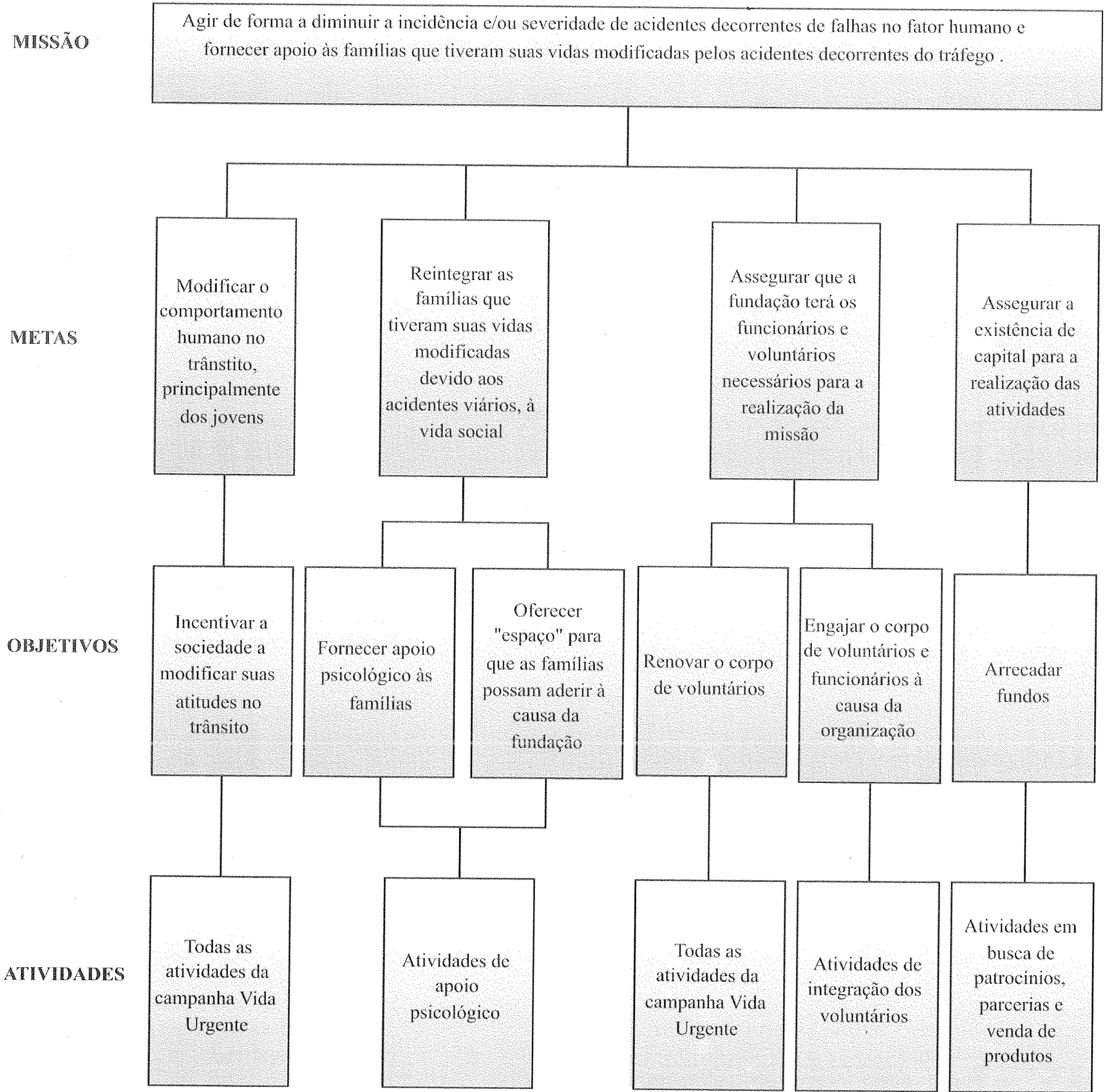

Figura 3. Relação entre a missão, metas, objetivos e atividade da FTMG (Diógenes, 2004). 
recursos; e (iii) a seleção de um número extenso de indicadores reduz a efetividade do sistema, visto que fica difícil basear os processos decisórios em muitas variáveis.

Assim, os princípios que orientaram a seleção dos indicadores da FTMG foram: (i) serem de fácil medição; (ii) serem representativos e relevantes para mensurar o alcance dos objetivos organizacionais; (iii) permitirem a avaliação específica das atividades e (iv) não onerarem significativamente a realização das atividades.

A seleção dos indicadores deu-se por duas etapas: (i) seleção preliminar; e (ii) seleção final. A seleção preliminar fundamentou-se na revisão da literatura, na análise das atividades e na identificação dos objetivos organizacionais. Para elaboração do sistema de indicadores, foram realizadas reuniões com membros da FTMG com o objetivo de incorporar a experiência vivenciada pela Organização. Foi através destas reuniões que se obteve informações sobre a existência de dados ou a possibilidade de coletá-los. Também foi possível inferir se a FTMG estava de acordo com os indicadores que estavam em processo de construção.

Para a seleção final foram feitas quatro perguntas aos membros da FTMG: (i) existiam dados para alimentar o indicador?; (ii) seria possível coletar os dados para o indicador?; (iii) a coleta de dados oneraria a Organização de tal forma que a inviabilizasse?; e (iv) o entrevistado acreditava que seria relevante utilizar o indicador? Ao final, o entrevistado foi encorajado a emitir sugestões.

Como resultado da consulta, todos os indicadores resultantes da seleção preliminar foram considerados relevantes, viáveis e necessários, embora os dados requeridos para os indicadores ainda não fossem coletados na maioria dos casos. Os entrevistados ainda sugeriram três novos indicadores que foram acrescentados ao sistema de indicadores (Diógenes, 2004).

Para melhor compreensão dos indicadores selecionados, eles foram descritos em fichas metodológicas. Estas estão baseadas no guia de indicadores urbanos, desenvolvido pelas Nações Unidas (UNCHS, 2001). Cada ficha é composta por oito campos, conforme Tabela 1.

Tabela 1. Descrição dos elementos das fichas metodológicas.

\begin{tabular}{ll}
\hline \multicolumn{1}{c}{ Campo } & \multicolumn{1}{c}{ Descrição } \\
\hline Indicador & Nome dado ao indicador \\
\hline Objetivo de origem & $\begin{array}{l}\text { Objetivo organizacional que possui } \\
\text { relação direta com o indicador proposto }\end{array}$ \\
\hline Definição & \begin{tabular}{l} 
Descrição do indicador \\
\hline $\begin{array}{l}\text { Atividades } \\
\text { vinculadas }\end{array}$
\end{tabular} $\begin{array}{l}\text { Atividades que estão sendo mensuradas } \\
\text { pelo indicador }\end{array}$ \\
\hline Significância & $\begin{array}{l}\text { Relevância do indicador para mensurar o } \\
\text { objetivo de origem }\end{array}$ \\
\hline Função de cálculo & $\begin{array}{l}\text { Fórmula utilizada para calcular o } \\
\text { indicador }\end{array}$ \\
\hline $\begin{array}{l}\text { Metodologia de } \\
\text { coleta de dados }\end{array}$ & $\begin{array}{l}\text { Forma como devem ser coletados os } \\
\text { dados. }\end{array}$ \\
\hline Periodicidade & Base de atualização da coleta dos dados \\
\hline
\end{tabular}

Para a atividade Madrugada Viva foram propostos 3 indicadores. Esta atividade atende a dois objetivos organizacionais: (i) incentivar a sociedade a modificar suas atitudes no trânsito; e (ii) renovar o corpo de voluntários da FTMG.

A proposição dos indicadores para a atividade Madrugada Viva atentou-se ao fato de que os próprios voluntários da atividade pudessem coletar os dados. As Tabelas 2, 3 e 4 apresentam os três indicadores selecionados para avaliar o alcance dos objetivos relacionados à atividade Madrugada Viva. O indicador constante da Tabela 2 é um indicador de resultado enquanto os demais são indicadores de saída da atividade.

Os indicadores aqui propostos ainda não foram implementados na Fundação Thiago de Moraes Gonzaga. Porém, esforços estão sendo gerados para que a adoção destes indicadores, e dos indicadores propostos por Diógenes (2004), seja realizada.

Tabela 2. Indicador vinculado à atividade Madrugada Viva 01.

\begin{tabular}{|c|c|}
\hline Indicador & $\begin{array}{l}\text { Participantes das atividades não envolvidos } \\
\text { em acidentes envolvendo excesso de bebida } \\
\text { alcoólica ou velocidade }\end{array}$ \\
\hline $\begin{array}{l}\text { Objetivo de } \\
\text { origem }\end{array}$ & $\begin{array}{l}\text { Incentivar a sociedade a modificar suas } \\
\text { atitudes no trânsito }\end{array}$ \\
\hline & Madrugada Viva \\
\hline Definição & $\begin{array}{l}\text { Percentual de participantes da Madrugada } \\
\text { Viva não envolvidos em acidentes, cujo } \\
\text { motivo foi a combinação álcool ao volante } \\
\text { ou altas velocidades. (só são considerados os } \\
\text { acidentes após a participação na atividade). }\end{array}$ \\
\hline Significância & $\begin{array}{l}\text { O aumento do percentual de participantes da } \\
\text { Madrugada Viva que não se envolveram em } \\
\text { acidentes, significa que o objetivo de } \\
\text { conscientização está sendo alcançado. }\end{array}$ \\
\hline $\begin{array}{l}\text { Função de } \\
\text { cálculo }\end{array}$ & \begin{tabular}{|lr}
$\mathrm{n}^{\circ}$. de participantes da Madrugada & Viva \\
entrevistados não envolvidos em & es \\
acidentes $/ \mathrm{n}^{\circ}$. total de participantes da \\
Madrugada Viva entrevistados
\end{tabular} \\
\hline $\begin{array}{l}\text { Metodologia de } \\
\text { coleta de dados }\end{array}$ & $\begin{array}{l}\text { Durante a Madrugada Viva, devem ser } \\
\text { escolhidas, aleatoriamente, algumas pessoas. } \\
\text { Estas devem informar nome, e-mail e } \\
\text { telefone. Após cada ano deve-se entrar em } \\
\text { contato com estas pessoas para saber se elas } \\
\text { se envolveram em acidentes. } \\
\text { Os dados são acumulativos, ou seja, se no } \\
\text { primeiro ano de coleta foram entrevistados } \\
20 \text { pessoas e depois de um ano } 1 \text { pessoa se } \\
\text { envolveu em acidentes, e depois de } 5 \text { anos, } \\
\text { mais } 3 \text { destes entrevistados se envolveram } \\
\text { em acidentes, o cálculo deverá ser (20- } \\
(3+1)) / 20)=80 \% \text {. Isto é feito para refletir a } \\
\text { efetividade da ação em longo prazo. Desta } \\
\text { forma os indicadores podem ser assim } \\
\text { apresentados: no ano } 2000 \text {, 95\% dos } \\
\text { entrevistados de } 1999 \text { não sofreram } \\
\text { acidentes envolvendo o problema álcool- } \\
\text { direção; no ano } 2005,80 \% \text { dos entrevistados } \\
\text { de } 1999 \text { não se envolveram em acidentes de } \\
\text { trânsito envolvendo o problema álcool- } \\
\text { direção. }\end{array}$ \\
\hline $\begin{array}{l}\text { Periodicidade de } \\
\text { cálculo } \\
\end{array}$ & $\begin{array}{l}\text { Anualmente e a cada cinco anos (dados } \\
\text { acumulativos) }\end{array}$ \\
\hline
\end{tabular}


Tabela 3. Indicador vinculado à atividade Madrugada Viva 02.

\begin{tabular}{l|l}
\hline Indicador & $\begin{array}{l}\text { Taxa anual de jovens que passaram pelo } \\
\text { teste do bafômetro }\end{array}$ \\
\hline $\begin{array}{l}\text { Objetivo de } \\
\text { origem }\end{array}$ & $\begin{array}{l}\text { Incentivar a sociedade a modificar suas } \\
\text { atitudes no trânsito }\end{array}$ \\
\hline $\begin{array}{l}\text { Atividades } \\
\text { vinculadas }\end{array}$ & Madrugada Viva \\
\hline Definição & $\begin{array}{l}\mathrm{n}^{\circ} \text {. de jovens que fizeram o teste do } \\
\text { bafômetro na Madrugada Viva por ano. }\end{array}$ \\
\hline $\begin{array}{l}\text { Significância } \\
\text { O aumento do no de jovens que fazem o } \\
\text { teste do bafômetro indica que as açóes da } \\
\text { Madrugada Viva estão aumentando a sua } \\
\text { amplitude. }\end{array}$ \\
\hline $\begin{array}{l}\text { Função de } \\
\text { cálculo }\end{array}$ & $\begin{array}{l}\mathrm{n}^{\circ} \text {. de jovens que fizeram o teste do } \\
\text { bafômetro na Madrugada Viva/ano }\end{array}$ \\
\hline $\begin{array}{l}\text { Metodologia de } \\
\text { coleta de dados }\end{array}$ & $\begin{array}{l}\text { Deve-se ter um voluntário ao lado dos testes } \\
\text { levantando o no de jovens que fizeram o } \\
\text { teste. }\end{array}$ \\
\hline $\begin{array}{l}\text { Periodicidade de } \\
\text { cálculo }\end{array}$ & \begin{tabular}{l} 
Anualmente \\
\hline
\end{tabular}
\end{tabular}

Tabela 4. Indicador vinculado à atividade Madrugada Viva 03.

\begin{tabular}{|c|c|}
\hline Indicador & Atração de voluntários \\
\hline $\begin{array}{l}\text { Objetivo de } \\
\text { origem }\end{array}$ & $\begin{array}{l}\text { Incentivar a sociedade a modificar suas } \\
\text { atitudes no trânsito }\end{array}$ \\
\hline Definição & $\begin{array}{l}\text { Percentual de voluntários atraídos } \\
\text { anualmente pela Madrugada Viva. Os } \\
\text { voluntários atraídos são aqueles que se } \\
\text { cadastraram na FTMG após terem } \\
\text { participado de uma determinada atividade da } \\
\text { Fundação. }\end{array}$ \\
\hline $\begin{array}{l}\text { Atividades } \\
\text { vinculadas }\end{array}$ & Madrugada Viva \\
\hline Significância & $\begin{array}{l}\text { Presume-se que, se o voluntário está se } \\
\text { cadastrando, ele é consciente dos perigos da } \\
\text { imprudencia no trânsito. Assim, ele não iria } \\
\text { dirigir sob o efeito do álcool, em altas } \\
\text { velocidades ou sem o cinto de segurança. Se } \\
\text { ele está sendo atraído por determinada } \\
\text { atividade, significa que a ação está atingindo } \\
\text { seus objetivos de conscientização. }\end{array}$ \\
\hline $\begin{array}{l}\text { Função de } \\
\text { cálculo }\end{array}$ & $\begin{array}{l}\mathrm{n}^{\circ} \text {. de voluntários atraídos pela Madrugada } \\
\text { Viva no ano } / \mathrm{n}^{\circ} \text {. de voluntários cadastrados } \\
\text { no ano }\end{array}$ \\
\hline $\begin{array}{l}\text { Metodologia de } \\
\text { coleta de dados }\end{array}$ & $\begin{array}{l}\text { Os formulários de cadastramento devem } \\
\text { conter obrigatoriamente dois campos: um } \\
\text { onde as pessoas dizem o que as levou a } \\
\text { serem voluntárias da FTMG, e outro onde } \\
\text { consta o ano de cadastramento. Estes } \\
\text { campos devem ter obrigatoriedade de } \\
\text { preenchimento. } \\
\text { Estes dados já são coletados, mas ainda não } \\
\text { são sistematizados. }\end{array}$ \\
\hline $\begin{array}{l}\text { Periodicidade de } \\
\text { cálculo }\end{array}$ & Anua \\
\hline
\end{tabular}

\section{CONCLUSÃO}

Os indicadores de desempenho representam uma abstração da realidade, onde informações compiladas propiciam o surgimento de questionamentos sobre a eficiência e eficácia de uma organização. A partir destes questionamentos, é possível detectar problemas e fornecer subsídios para a busca de alternativas que gerem bons resultados.

A realização deste trabalho permitiu constatar que são inúmeros os indicadores que podem ser aplicados para avaliar a segurança viária, não existindo uma regra para a seleção destes. De forma resumida, os indicadores selecionados devem ser simples, representativos e relevantes, estando diretamente relacionados aos objetivos organizacionais. Além disso, eles devem fornecer informações para melhor entendimento dos processos e identificação das causas dos problemas, provendo a visibilidade necessária para orientar as ações de melhoria de desempenho.

É comum encontrar ações de segurança viária sendo desenvolvidas sem que haja uma análise de eficiência ou eficácia monitorada por indicadores. Tende-se a mensurar o nível de segurança viária por meio de dados provenientes de fontes incompletas ou mal depuradas, como, por exemplo, número de acidentes fatais por frota veicular. A falta de conhecimento sobre o efeito das ações contribui para que as organizações desperdicem recursos. A formulação de estratégias aliadas à criação de um sistema de indicadores de desempenho é indispensável a melhor atuação das organizações que atuam na área de segurança viária.

A seleção dos indicadores é apenas a primeira etapa no processo de avaliação de desempenho de qualquer organização. É sempre importante ressaltar que indicadores não podem ser considerados medidas objetivas sem erros ou problemas de definição e interpretação. Somente uma análise a ser realizada depois da adoção de um sistema de indicadores permitirá identificar se este é realmente adequado, tanto no que se refere à avaliação do alcance dos objetivos como à implementação do processo de coleta e armazenamento dos dados.

\section{REFERÊNCIAS BIBLIOGRÁFICAS}

Aeron-Thomas, A. (2003) Community Traffic Policing Scoping Study: Final Report. TRL Limited, Crowthorne, Inglaterra.

Aeron-Thomas, A. A. J. Downing; G. D. Jacobs; J. P. Fletcher; T. Selby e D. T. Silcock (2002) Review of Road Safety Management Practice: Final Report. TRL Limited, Crowthorne, Inglaterra.

Amouzou, K.D. e E.M. Pérez (1999) O Paradigma Organizacional: Análise de Alguns Conceitos de Alta Administração para Performance. Anais do 23 Encontro Anual da Associação Nacional dos Programas de Pósgraduação em Administração, EnANPAD, Foz do Iguaçu. Disponível em <http://www.informal.com.br/artigos/ AE08.htm>. Acesso em: 02 jun. 2003.

Campos, V.F. (1992) TQC: Controle da Qualidade Total (no Estilo Japonês) (2 $2^{\text {a }}$ ed.). Ed. Bloch, Rio de Janeiro.

Carvalho, C.A.P. (1999) Preservar a Identidade e Buscar Padrões de Eficiência: Questões Complementares ou Contraditórias na Atualidade das Organizações Não Governamentais. Anais do $23^{\circ}$ Encontro Anual da Associação Nacional dos Programas de Pós-graduação em Administração, EnANPAD, Foz do Iguaçu. Disponível em <http://www.informal.com.br/artigos/AE08.htm>. Acesso em: 02 jun. 2003. 
Diógenes, M.C. (2004) Indicadores de Desempenho no Gerenciamento da Segurança Viária. Dissertação (Mestrado em Engenharia de Produção) - Programa de Pós-graduação em Engenharia de Produção, Universidade Federal do Rio Grande do Sul, Porto Alegre.

Diógenes, M.C. e L. A. Lindau (2003) Estruturando a Geração de Indicadores de Segurança Viária. Anais do XVII Congresso Pesquisa e Ensino em Transportes, ANPET, Rio de Janeiro, v.1, p. 542-553.

Ellevset, L.A (1997) The Role of NGOs in Road Safety. Anais eletrônicos do World Bank Seminar on Road Safety. World Bank, Bangladesh. Disponível em: <http:// www.worldbank.org/html/fpd/transport/> Acesso $\mathrm{em:} 08$ set. 2003.

ETSC (2001a) Sharing Responsibilities for Road Safety. European Transport Safety Council, Bruxelas. Disponível em: <http:/ /www.etsc.be>. Acesso em: 06 nov. 2002.

ETSC (2001b) Transport Safety Performance Indicators. European Transport Safety Council, Bruxelas. Disponível em: <http:/ /www.etsc.be>. Acesso em: 10 nov. 2002.

Ferlauto, D. (1996) Thiago Gonzaga: Histórias de uma Vida Urgente (12 ${ }^{\mathrm{a}}$ ed.). Editora Didacta, Porto Alegre.

Gonzaga, M. E. M. (2003) [Depoimento] In: Freitas, A. V. Em Busca do Sonho: Questão de Saúde Pública. Jornal da Univeridade Federal do Rio Grande do Sul, n.62, ano 5. Disponivel em: <http://www.ufrgs.br/jornal/maio2003/>. Acesso em: 15 out. 2003.

JAT - Joint Authors Team (2000) National Programme of Road Safety Improvement in Poland: GAMBIT. National Road Safety Council, Gdansk, Polônia. Disponível em: <http:// www.gambit.org.pl/>. Acesso em: 10 nov. 2002.

Kroj, G. (2000) New Approaches to Road Traffic Safety in Germany. Proceedings of the Congress Road Safety on Three Continents, Swedish National Road and Transport Research Institute, Pretoria, África do Sul.

Lord, J. (2000) Really MADD: Looking back at 20 Years. Driven, spring 2000. Disponível em: <http://www.madd.org/news/ $>$. Acesso em: 19 out. 2003.

Lötter, S. (2000) Road Safety Diagnostic System for South Africa. Dissertação (Mestrado em Engenharia). Linköping Institute of Technology, Linköping University, Suécia.
LTSA (1998) Safety Directions: an International Comparison of Road Safety Enforcement. Working paper 3 Land Transport Safety Authority, Wellington, Nova Zelândia.

MADD (2003) [Informações sobre a MADD]. Mothers Against Drunk Driving, USA. Disponível em: <http:// www.madd.org $>$. Acesso em: 03 out. 2003.

Norwood, J. e J. Casey (2002) Key Transportation Indicators: Sumary of a Workshop. National Research Council. Division of Behavioral and Social Sciences and Education. National Academy Press, Washington, D. C.

OECD (2002) Safety On Roads: What's the Vision? Road Transport and Intermodal Linkage Research Programme (RTR), Organisation for Economic Co-Operation And Development, Paris. ISBN 92-64-19681-1.

OMS (2002) A 5-Year WHO Strategy for Road Traffic Injury Prevention. Organização Mundial de Saúde, Gênova, Suíça.

Peden, M.; R. Scurfield; D. Sleet; D. Mohan; A. A. Hyder; E. Jarawan e C. Mathers (2004) World Report on Road Traffic Injury Prevention. Organização Mundial de Saúde, Gênova, Suíça.

Rumar, K. (1999) Transport Safety Visions, Targets and Strategies: Beyond 2000. Introduction to the European Transport Safety Lecture. European Transport Safety Council, Bruxelas, Bélgica.

Stenborg, L. (1999) Performance Indicators for Traffic Safety (Draft Proposal). Borlänge, Suécia.

The Globe (2003) Drinking and Driving in Europe. Global Alcohol Policy Alliance (GAPA), Londres, Inglaterra. ISSN 14609142.

UNCHS (2001) Guide to Urban Indicators. United Nations Commission on Human Settlements, Nova York. Disponível em: <http://www.unhabitat.org/programmes/ guo/guo_guide.asp $>$. Acesso em: 20 out. 2003.

Volvo (2003) [Informações sobre a Volvo]. Volvo, Brasil. Disponível em: <http://www.volvo.com.br>. Acesso em: 03 mar. 2004.

World Bank (1996) Performance Monitoring Indicators: a Handbook for Task Managers. Operations Policy Department, World Bank, Washington, D. C.

\section{CONTATOS}

${ }^{1}$ Nome: Mara Chagas Diógenes

E-mail: maracd@producao.ufrgs.br
2Nome: Luis Antonio Lindau

E-mail: lindau@producao.ufrgs.br 